\title{
Women who give birth before arriving at National District Hospital in Bloemfontein, Free State
}

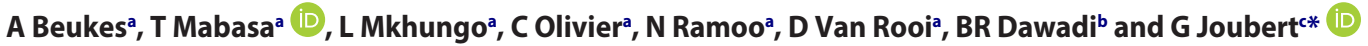 \\ ${ }^{a}$ Faculty of Health Sciences, School of Medicine, University of the Free State, Bloemfontein, South Africa \\ ${ }^{b}$ Faculty of Health Sciences, Department of Family Medicine, University of the Free State, Bloemfontein, South Africa \\ 'Faculty of Health Sciences, Department of Biostatistics, University of the Free State, Bloemfontein, South Africa \\ *Corresponding author, email: gnbsgj@ufs.ac.za
}

Background: Birth before arrival (BBA) contributes to the neonatal death rate in South Africa. This study aimed to determine the profile of and reasons for women giving birth prior to arrival at National District Hospital, Bloemfontein.

Methods: This was a descriptive study of women, 18 years or older, presenting with BBA at National District Hospital between October 2015 and January 2016. Consenting women were interviewed by the discharging doctor who completed the questionnaire.

Results: Of the 68 mothers with BBAs, 61 were included (response rate 90\%). The highest percentage (38\%) lived less than $5 \mathrm{~km}$ from a healthcare facility. The median parity was three and $67 \%$ gave birth unexpectedly. Common factors were poor antenatal clinic booking and limited antenatal clinic visits. Most mothers (89\%) depended on Emergency Medical Services and 69\% had made no prior arrangements with a hospital.

Conclusion: Better education on antenatal care and delivery planning is recommended.

Keywords: birth before arrival, district hospital, factors, patient profile

\section{Introduction}

Perinatal and neonatal mortality rates in South Africa are high ${ }^{1}$ and birth before arrival (BBA) can be a contributing factor. ${ }^{2}$ In 2014, 306 babies were born before the mothers arrived at National District Hospital in Bloemfontein, Free State. ${ }^{3}$ This study aimed to determine the profile of and reasons for women giving birth prior to arrival at National District Hospital.

\section{Methods}

This was a descriptive study on consecutive women, 18 years or older, presenting with a BBA at National District Hospital between October 2015 and January 2016. The mothers gave written informed consent to be interviewed by a medical intern, acting as the discharging doctor, who completed the questionnaire, available in Afrikaans, English or Sesotho, that was coded and analysed by the student researchers. A pilot study was performed on 10 mothers, who were included in the main study. The only problem identified was the omission of recording the birthweight on the questionnaire by the discharging doctor. This was communicated to the discharging doctor to be rectified. No adjustments needed to be made to the questionnaire based on the pilot study. The study was approved by the Ethics Committee of the Faculty of Health Sciences, University of the Free State and the Free State Department of Health.

\section{Results}

Of the 68 mothers with BBAs who presented at National District Hospital during the study period, 61 were included (response rate $90 \%$ ). Six mothers did not sign consent and one mother was under the age of 18 . Nearly half of the mothers (49\%) were 30 years and older and 39\% had Grade 10 or higher education. More than a third (38\%) lived less than $5 \mathrm{~km}$ from a healthcare facility and $15 \%$ lived more than $15 \mathrm{~km}$ from a healthcare facility.
The median parity was three and $15 \%$ of the mothers were nulliparous. Most (72\%) knew the duration of their pregnancy, mainly by 'sure date'. The gestational age of $51 \%$ of the mothers was between 37 and 41 weeks, and $67 \%$ indicated that they gave birth unexpectedly.

Common factors in the study group were poor antenatal clinic booking (32\% were not booked), limited antenatal clinic visits (median four visits), unwanted/unplanned pregnancies (28\%) and smoking during pregnancy (39\%). Most mothers (89\%) depended on Emergency Medical Services (EMS) and almost $49 \%$ waited over two hours for EMS to arrive. A high percentage of women (69\%) had made no prior arrangements with a hospital regarding delivery of the present pregnancy. The majority (84\%) had no personal, cultural, religious or family beliefs against delivering their baby at a hospital. There were one neonatal death and two stillbirths among the 61 BBAs.

\section{Discussion}

The number of antenatal clinic visits was low, and few mothers had made specific arrangements for the delivery, despite this being a group of women who had a median parity of three. Better education of pregnant women on antenatal care and delivery planning is recommended. The high dependence on EMS indicates the continued need for this service to be functioning efficiently.

Prominent factors such as cultural beliefs found in a study in Malawi $^{4}$ and half (54\%) of BBA mothers not booked in a study in Pietermaritzburg ${ }^{2}$ were not as common in our study. Distance from a healthcare facility, as highlighted in an Eastern Cape study, ${ }^{5}$ or mothers with transport problems were not factors that were as common as expected. 
The small study sample of this quantitative study does not allow for statistical sub-analyses, and similar investigations should consider using a qualitative approach.

Acknowledgements - The authors thank all participating mothers, medical interns and Dr M. Malek of National District Hospital for their cooperation. Ms T. Mulder, medical editor, School of Medicine, University of the Free State, is thanked for technical and editorial preparation of the manuscript.

Conflict of interest - The authors declare that they have no financial or personal relationships that may have inappropriately influenced them in writing this article.

\section{ORCID}

T Mabasa (iD http://orcid.org/0000-0003-1955-9667

G Joubert (iD http://orcid.org/0000-0002-3728-6925

\section{References}

1. Wang $\mathrm{H}$, Liddell $\mathrm{CA}$, Coates $\mathrm{MM}$, et al. Global, regional, and national levels of neonatal, infant, and under-5 mortality during 1990-
2013: a systematic analysis for the Global Burden of Disease Study 2013. Lancet. 2014;384:957-79. http://dx.doi.org/10.1016/S01406736(14)60497-9.

2. Parag N, McKerrow NH, Naby F. Profile of babies born before arrival at hospital in a peri-urban setting. S Afr J Child Health. 2014;8(2):45-9. doi:10.7196/SAJCH.681.

3. National District Hospital. Monthly maternity statistics record. Maternity Ward. Unpublished internal document. National District Hospital, Free State, South Africa. 2014.

4. Kumbani L, Bjune G, Chirwa E, Malata A, Odland Jø. Why some women fail to give birth at health facilities: a qualitative study of women's perceptions of perinatal care from rural Southern Malawi. Reprod Health. 2013;10:9. doi:10.1186/1742-4755-10-9.

5. Alabi AA, O'Mahony D, Wright G, Ntsaba MJ. Why are babies born before arrival at health facilities in King Sabata Dalindyebo Local Municipality, Eastern Cape, South Africa? A qualitative study. Afr J Prim Health Care Fam Med. 2015;7(1):881. doi:10.4102/phcfm. v7i1.881. 